\title{
La muralla islámica de Málaga: Referencias textuales y constatación arqueológica
}

\author{
M. Carmen Îniguez Sánchez
}

\section{INTRODUCCIÓN}

El estudio de la muralla de Málaga es un tema lo suficientemente complejo, por lo que las siguientes páginas tratan sólo de una primera aproximación a su estudio, constituyendo una puesta al día, tras los últimos avances arqueológicos respecto a origen, morfología, transformación y cronología.

En el mismo se conjugan distintos aspectos, ya que no se trata de un elemento inamovible, sino que como parte integrante de la ciudad, está sometida a la propia dinámica urbana, tanto en el mundo islámico como en el posterior cristiano.

Dos conceptos convergen en la configuración de la muralla, el propiamente defensivo, integrado por lienzos de muros, que podían o no estar almenados, jalonados de torres cuadradas o semicirculares, la barbacana o antemuro que se sitúa a una distancia próxima delante de la muralla y de menor altura que ésta y el foso que discurre entre ambas. Y el segundo, de comunicación, al que corresponden las diversas puertas de entrada y salida de la ciudad, que como elemento más vulnerable solía flanquearse de sendas torres y con puesto interior de vigilancia. Obviamos una descripción pormenorizada

\section{INTRODUCCIÓN HISTÓRICA}

Tras la conquista de Málaga, 7| |-7|3, según las fuentes (ACIÉN 1984a y b) se produce en los primeros momentos, una colaboración de los árabes asentados en la ciudad con el estado de Córdoba, siendo durante el Emirato su importancia relativa, frente a Bezmiliana (ACIÉN 1986) y Archidona, capital entonces de la kura.

Dos elementos caracterizan el Califato, la configuración de las estructuras estatales y una vez pacificado el territorio, la falta de problemas internos.

Málaga, ya como capital de la kura, adquirirá mayor notabilidad, que se verá incrementada, tras la crisis del Califato, con el establecimiento de la dinastía Hammudí en los inicios del siglo XI, para pasar a depender de los ziríes de Granada y, posteriormente de los imperios almorávide y almohade, sucesivamente, hasta mediados del siglo XIII en que formará parte del Reino nazarí de Granada. Tras un breve período de esplendor comercial, en el que destacamos la importancia de su puerto (LADERO 1979), incrementada por la decadencia de Almería y la apertura del Estrecho, se verá inmersa en la problemática de la conquista cristiana.

Esta breve introducción histórica, no es gratuita, sino básica a la hora de interpretar la edificación de la muralla, ya que su factura y trazado es paralelo a la secuencia histórica de la ciudad. 


\section{ESTUDIO HISTÓRICO}

Para el estudio de la muralla de Málaga contamos, en primer lugar con las fuentes documentales, tanto musulmanas como cristianas, sin olvidar a los eruditos locales, que siempre nos aportan noticias significativas. A esto, tenemos que añadir la propia topografía urbana de la ciudad, así como la toponimia, que ha mantenido en sus calles nombres bastante alusivos, por citar algunos ejemplos, los que hacen referencia a puertas o postigos: Puerta de San Buenaventura, de Antequera, Nueva, del Mar, Postigo de Arance, de los Abades, Muro de San Julián, de Santa Ana, etc...

La muralla que cercaba la madina, en época Nazarí (Lám. I), partía de la Alcazaba, a la que no envolvía', en línea más o menos recta (su trazado iría por las actuales calles de Muro de Santa Ana, Plaza de M $^{a}$ Guerrero), hasta enlazar con la Puerta de Granada, que quedaría situada un tanto desplazada del inicio de la calle que actualmente conocemos con tal nombre y que fue tapiada debido a las torrenteras que bajaban por calle de la Victoria (GUILLÉN 1984), con posterioridad al siglo XVII (AMATE 1988, p. 88). Su trazado continuaba por la acera izquierda de la Plaza de la Merced (PASTOR, PÉREZ 1983), prosiguiendo por C/ Alamos, conectando aquí con el muro que cercaba el arrabal de Fontanella, que se extendía entre las actuales calles Frailes, Refino, Postigo, Molinillo y Goleta ${ }^{2}$ y dedicados sus habitantes a la fabricación de cerámica, topónimo mantenido en una de sus calles, Ollerías
(ACIÉN, PERAL, RECIO 1989-90). Continuaba hasta la Puerta de San Buenaventura, calle que aún hoy conserva su nombre, y que identificamos con la puerta musulmana que conectaba con el arrabal de Fontanella. Dicha puerta sufre modificaciones durante el siglo XVII (AMATE 1988, p.98) y la misma pudo ser apreciada por Guillén Robles (1984, p. 477) antes de su demolición en el siglo XIX. A partir de aquí se bajaba, haciendo ángulo por $\mathrm{Cl}$ Carretería hasta la puerta de Antequera. En este tramo se localiza en 1987 un torreón adelantado de época nazarí, durante el proceso de rehabilitación del palacio de Valdeflores, ${ }^{3}$ actual sede del Instituto de la Mujer.

La puerta de Antequera ${ }^{4}$ constituía una de las salidas más importantes de la ciudad. A continuación proseguía el tramo de muralla hasta enlazar con el Pasillo de Santa Isabel ${ }^{5}$, donde se situaría la puerta de la Puente, desconociéndose su ubicación exacta (GUILLÉN 1984, p. 473). Conectaba con las atarazanas a las que se adosaba ${ }^{6}$ y siguiendo la línea costera enlazaba con el espigón natural de la plaza de La Marina ${ }^{7}$, donde se emplazaba el castill de los genoveses, dejando atrás las puertas del Mar, Baluarte, Espartería y de los Siete Arcos, que comunicaban la ciudad con la ensenada del puerto.

Su recorrido seguía ${ }^{8}$ por la actual calle Cortina del Muelle, bordeando la línea costera hasta enlazar con el conjunto de la Alcazaba, a cuya Haza se abrían dos puertas, la de la Caba y Puerta Oscura?.

\footnotetext{
I Tan importante era en el mundo musulmán la salvaguarda de la Alcazaba del exterior como de la propia ciudad.

2 Descrito por lbn al-jatib y al-Idrisi, citado por GUILLÉN ROBLES, F. p. 47I.

3 La sección y una fotografía del mismo se puede ver en. MACHUCA SANTA-CRUZ, L (1987): Málaga, ciudad abierta. Origen, cambio y permanencia de una estructura urbana, Málaga, pp. 104-106.

4 Se conserva tal topónimo, pero desplazado del lugar de ubicación de la misma. Fue derribada en 1785 para dar mayor amplitud a la entrada del Convento de las Catalinas en F. Guillén Robles, p. 478.

5 NAVARRO LARA (1988) detecta un tramo de la muralla musulmana.

6 FERNANDEZ GUIRADO, M. I. (1988) igualmente localiza en la calle Sagasta una parte de la muralla de la ciudad.

7 Como así ha demostrado la excavación de urgencia efectuada en la Plaza de la Marina en 1988, dirigida por M. Acién Almansa a quien agradecemos nuestra participación como miembro del equipo técnico. Existe un informe : "Avance de la actuación de Urgencia en las obras de la Plaza de la Marina. Málaga-Casco Urbano. Abril/88". Inédito.

8 En la excavación de la Plaza de la Marina no se encontró el ángulo de muralla que conecta con este sector, probablemente más desplazado hacia el Este.

9 DE LA CERDA, E.: Planos comparativos de Málaga. Carpeta Archivo Municipal de Málaga. El plano lo recoge GUILLÉN ROBLES, F. p. 47I.
} 
La muralla, como anteriormente hemos señalado, presenta distintas etapas constructivas y continuas reparaciones, dependiendo de las necesidades defensivas de la ciudad, como así señalan las fuentes narrativas.

Según una Crónica islámica de los Muluk al-Tawaif, recogida por Torres Balbás (1934, p. 478 y 533; 1982, p. 179), fue Hasan alMustansir, hermano y sucesor de Idris I ( 1040- 1042), el que inicia la fortificación de la ciudad de Málaga.

Al-Bakri, la describe hacia 1068, circundada por una muralla con cinco puertas (TORRES BALBÁS 1934, p. 533).

Según `Abd Allah (GARCÍA GÓMEZ; LEVI-PROVENÇAL 1980, p. II4), cuyas memorias son una importante fuente coetánea, fue Badis, su abuelo, muerto en el último cuarto del siglo Xl, quien edifica la Alcazaba, y suponemos efectuaría trazados de la muralla, citando, en una de las escaramuzas la salida de las tropas por la puerta de la Fontanella (GARCÍA GÓMEZ, LEVI- PROVENÇAL, 1980, p. 186).

La muralla no es nombrada por al-Idrisi en el siglo XII (I974, p. 39).

Durante el mandato de Ibn Hud (12281237) (VALLVÉ 1966, p. 263), Ibn Zannun fortifica y repara las murallas del recinto abriendo una salida delante de la puerta de Bab Funtanalla y restaura la puerta de los Vientos (Bab al Riwah), cuya ubicación desconocemos.

Será en el siglo XIV cuando tanto Muhammad IV (I325-I333) como Yusuf I (1333-1354), consoliden Gibralfaro y la Alcazaba realizando la coracha que une ambos conjuntos (CHABANA 1968, pp. 179), y se repare y amplíe el recinto murado de la ciudad.

Ibn al Jatib (1977, p. I |6-। | 9) nos describe la alcazaba, protegida por doble y fuerte muralla pero obvia la protección urbana.
EL cronista de los Reyes Católicos, Hernando del Pulgar, hace la siguiente descripción de Málaga en el momento de la conquista:

"Está asentada en un lugar llano, al pie de una cuesta grande, e es cercada de un muro redondo, fortalecido de muchas torres gruesas, e cercanas unas de otras; e tiene una barrera alta e fuerte do asimismo ay muchas torres. E al cabo de la Cibdat, e al comienço de la subida de la cuesta está fundado un alcaçar, que se dize el Alcaçaba, cercado con dos cercas podimos contar fasta treynta e dos torres gruesas, de maravillosa altura e artificio conpuestas. E allende destas, tiene en el circuito de los dos muros fasta otras ochenta torres medianas e menores, cercanas unas de otras" (MATA CARRIAZO 1940, pp. 283-284).

Suponemos que Pulgar se refiere al recinto murado del arrabal de Fontanella, cuando cita un "....muro redondo, fortalecido de muchas torres gruesas, e cercanas unas de otras...", siendo la muralla propiamente dicha "...una barrera alta e fuerte do asymismo ay muchas torres.."

Tras la conquista, las fuentes cristianas nos aportan los intentos de reparar las murallas de la ciudad realizados por los Reyes Católicos mediante la emisión de una serie de documentos, en I494 (MORALES 1906, I, p. 104), para reparar las torres y muros dañadas por un terremoto. En I 497 (MORALES 1906, I, p. |7|), otorgando una serie de rentas para igualmente reparar los muros del daño ocasionado por la artillería durante la conquista, en 1500, para que prosigan las reparaciones (MORALES, I 906 II, p. 20) y en I50I, obligando a los oficios del barro a pagar el diezmo para el arreglo de las murallas (MORALES, |906, II, pp. |49-|5|).

Es indudable que los primeros daños sufridos por la muralla se deben a la artillería durante la conquista, como anteriormente ha quedado reflejado. A partir de aquí sufrirá, dependiendo de la situación topográfica de su trazado, una serie de transformaciones. 
Mientras que la orientada al mar, es decir, la que discurre desde la alcazaba hasta las Atarazanas, se mantendrá y será constantemente reparada por las necesidades de la defensa de la plaza en los siglos XVI y XVII, e incluso incrementada, como es el caso de la construcción del Torreón del Obispo ${ }^{10}$, El tramo orientado al interior y al río empezará a sufrir prontas modificaciones, los Repartimientos (BEJARANO 1984; 1985) ya recogen la cesión de solares enfrente de la muralla para casas y conventos, como el sitio para edificar el convento de San Francisco por Real Cédula de 27 de octubre de 1489 de los Reyes Católicos (GARCÍA DE LA LEÑA I98I, III, p. 233).

E igualmente se habilita alguna puerta y postigo de nueva factura en su recorrido, como es el caso de Puerta Nueva, siendo corregidor Pedro Gómez de Torres, en 1534 (GARCÍA DE LA LEÑA, I98I, Il, p. 203).

En época de Felipe II, el corregidor Mendo Rodríguez de Ledesma hace que dos regidores y dos alarifes:

"...viesen y tanteasen el daño de las dichas murallas y declarasen la forma y estado en que estaban y lo que costaría el reparo de ellas..."

A lo que aluden a uno de sus trazados:

"Las murallas que hay desde la puerta Nueva hasta la puerta que dicen de Antequera que mira por maestre tramontana en que hay seis torres con seis lienzos, costaran los materiales y manufactura de ellas mil ducados porque requieren mucho aderezo...."

Tal documentación que nos refleja el número de torres entre ambas puertas no hace sin embargo alusión a tipos de fábrica ni características de las mismas.
A pesar de esto el estado del recinto murado en época de Carlos II debía ser tan lamentable que el marqués de Villafiel (AMATE 1988, p. 78) informa "...del riesgo de esta Plaza por estar allanadas todas sus murallas..." (AMATE 1988, p. 78), por lo tanto se efectúa una reparación de muros y puertas, sobre todo, hojas de las mismas, aunque "...sin tocar al pulimento de su antigüedad... dejándolas con las memorias de su fábrica...". Demoliéndose no obstante el llamado postigo de las Abades, situado en la Cortina del Muelle, de probable origen cristiano (AMATE 1988, p. 92).

Poco a poco se fueron adosando casas por el interior a la muralla, el foso de la misma se había convertido en un estercolero, incluso la población abría agujeros en los lienzos para verter la basura directamente al foso' ${ }^{12}$.

Su situación tenía que ser lamentable, cuando y ante la amenaza de agresiones militares y avenidas del Guadalmedina (|66|), se encarga al arquitecto militar Hércules Torelli un plan de obras de fortificación que nunca se llevarían a cabo (OLMEDO 1986).

Para solucionar el problema y debido a la importancia urbanística que va adquiriendo el sector de Álamos y Carretería, el regidor Luis de Tolosa propone conceder gratuitos terrenos a vecinos que quisieran hacerse una casa en el tramo comprendido entre la puerta de Granada y puerta Nueva, con la obligación de limpiar la parte que le correspondiera de foso, que al final quedará convertido en una gran alcantarilla (BEJARANO 1984, I, 219; MORALES 1986, pp. 7I-76).

Es interesante hacer constar la descripción que hace de la muralla Guillén Robles que pudo observar algunos de sus tramos:

"...muestra diversas alturas y espesores, según la disposición del terreno y también según las

\footnotetext{
10 Localizado en la intervención realizada por nosotros en la Plaza de la Marina Junio-Julio 1987. Informe inédito.

II Este documento procede del Archivo General de Simancas, sección Guerra Antigua, leg. 266, recogido en CABRERA PABLOS, F. y OLMEDO CHECA, F. (1 988): El puerto de Málaga, Málaga, , p. 90.

I2 Tal documentación procede de los Libros Capitulares, vol. XVII, fol. 267v., recogido por BEJARANO I984 vol. I, p. 2 I6.
} 
exigencias de la defensa... Su construcción también es muy varia; parte de ella la mas escasa, especialmente muchas torres, son de cajones de hormigón: la mayor parte de cajones de tierra y piedra menuda bastante bien apisonada y endurecida, a veces se ven refuerzos de ladrillo provenientes de obras cristianas" (GUILLÉN 1984, pp. 480-482).

Respecto a la disposición de la misma

"...el muro estaba almenado y de trecho en trecho, bastante corto, lo defendían torres cuadradas y a veces semicirculares... Eran estas torres de piedra, de hormigón y aún de ladrillo..." (GUILLÉN I984, p. 480).

Es indudable que Guillén Robles apreció en la misma distintos momentos constructivos.

También menciona la existencia de otra muralla más baja que él denomina falsa braga, que identificamos con la barbacana. El foso, y el paso de ronda que sitúa, aún hoy puede comprobarse, incluso con un lienzo de muro, en las calles Muro de San Julián y Muro de las Catalinas (GUILLÉN 1984, p. 48I).

\section{ANÁLISIS ARQUEOLÓGICO.}

Para el estudio arqueológico nos basamos en sondeos de urgencia realizados hasta el momento en la ciudad, el primero de ellos, del año 1983 situado en la plaza de la Merced (PASTOR, PÉREZ 1983). Lindando con el río Guadalmedina, en el pasillo de Santa Isabel (NAVARRO 1988) y en calle Sagasta (FERNÁNDEZ 1988) los siguientes el año 1987. Y el último realizado en calle Alarcón Luján'³.

Hemos de mencionar que se trata de excavaciones limitadas por las características de los solares y por la duración de la inter- vención, por lo que la investigación también se ve limitada.

Además de los sondeos ya mencionados contamos con los datos obtenidos en la Plaza de la Marina ${ }^{14}$, que supone la excepción a lo anterior, ya que se trata de una excavación extensiva y con una secuencia estratigráfica completa, cosa que no ocurre, por ejemplo, en el corte de la plaza de la Merced.

Dependiendo de los tramos de muralla excavados encontramos distintos tipos de cimentación y distintos momentos constructivos (exceptuando plaza de la Marina y calle Sagasta)

La cimentación se realiza en la línea costera, directamente sobre la arena de la playa, en la que previamente se habrá efectuado una fosa, este es el caso de los tramos de la plaza de la Marina, Alarcón Luján y Sagasta. $O$ abriendo la fosa en el lecho del río como es el caso del Pasillo de Santa Isabel.

Mientras que en el tramo excavado en la Merced se haría un foso en el depósito de naturaleza antrópica de las diversas avenidas características, aún hoy en día, en dicho sector.

Las facturas de dichas cimentaciones responden a diversos momentos constructivos. En la Merced se advierten dos cimentaciones, la primera, debajo del lienzo de muralla, de tapial, que pensamos obra anterior a dicho paramento, pudiendo corresponder al siglo XI (GARCÍA GÓMEZ, LEVI-PROVENÇAL 1980, pp. II4 y |86). A intramuros en estratos inferiores al paso de ronda, según sus autores, se localiza una segunda cimentación, de grandes piedras cuadradas, desconocemos si se trataban de sillares, pero creemos que podían responder a la obra de época califal de la que recientemente se encontró un paramento en la calle Almacenes ${ }^{15}$.

\footnotetext{
13 PÉREZ-MALUMBRES, A: Sondeo Arqueológico en la muralla musulmana de Málaga en el solar de calle Alarcón Luján, n 3. En prensa. Agradezco a su autor la consulta del mismo.

14 Excavación realizada en la Plaza de la Marina, dirigida por M. Acién Almansa. Se prepara su publicación.

15 Nota de prensa. Diario Sur, I4-I-1993.
} 
El ejemplo más representativo nos lo proporciona la plaza de la Marina ${ }^{16}$ que por su homogeneidad constructiva y cronológica, en el momento nazarí describimos completo. Un gran lienzo de muralla con factura de mampostería, presentando al exterior restos de enlucido o revestimiento de ladrillo y al interior las huellas de los maderos que formaban los cajones que sostuvieron el mampuesto. Al exterior tenía adosados dos baluartes semicirculares que perdían tal forma a nivel de cimentación. La misma estaba constituida por una escollera fuertemente trabada y un entramado de vigas de madera, dispuestas tanto horizontal como verticalmente en la arena.

Similar homogeneidad y cronología presenta el tramo hallado en calle Sagasta, con la particularidad de su adosamiento al muro de las Atarazanas (FERNÁNDEZ 1988). La fábrica es de cajones de piedra con mortero de cal y arena separadas por hiladas de ladrillo, siendo también de este material la esquina. En la cimentación aparecen vigas de madera horizontales.

Más conflictivos son el resto de los paramentos detectados, el de la plaza de la Merced, de siete metros, sus autores lo datan en el siglo XIV por la similitud de su fábrica, de mampostería de ladrillo y pizarra al exterior y con mayor abundancia de piedras a intramuros, con el recinto exterior de la Alcazaba.

El tramo de Alarcón Luján supone un avance de la ciudad sobre la línea de costa, ya que el trazado de la muralla califal discurre más al interior. En la fosa de cimentación del mismo se pudo apreciar un estrato con materiales constructivos: teja, ladrillo, madera y cerámica quemados, quizás a fin de eliminar pequeñas estructuras asociadas a actividades pesqueras anteriores, como así lo recoge el autor de la excavación en su informe. La construcción muraria se presenta asociada a material almohade y nazarí, encontrándose deteriorada ya que ha perdido el paramento externo, se divide en tres partes transversalmente, la primera de mortero de cal, arena de playa, chinarro y arenisca, la parte central de ladrillo y la situada más al $\mathrm{N}$. con un relleno de piedras, que según su autor colmataría con otro alzado situado más al interior y que no se pudo apreciar en el sondeo (PÉREZMALUMBRES en prensa). Es posible que correspondan a reparaciones realizadas en la muralla tras la conquista.

La relación estratigráfica del corte situado junto al río Guadalmedina, se inicia con una serie de fragmentos de época califal de aporte, no asociado a ninguna estructura. En el mismo lecho del río, como ya se ha apuntado, se ejecuta la fosa para la cimentación, posiblemente de época almohade, ya que corresponde a este momento también el material cerámico asociado. La adscripción cronológica del alzado ya es más conflictiva debido a los tipos de factura que presenta. Al exterior de ladrillo y caliza, existiendo una clara diferenciación a intramuros, la primera obra de caliza y mortero, cuyos cajones se verán separados por hiladas de ladrillo en la parte superior del alzado.

La barbacana y el foso, sólo se ha localizado en el solar de la plaza de la Merced, la primera de 1,20 m de grosor, con factura de piedra y ladrillo, según sus autores efectuaba un ángulo de $90^{\circ}$ en dirección a la plaza que nosotros identificamos como la posible conexión con el arrabal de Fontanella que se encontraba murado. Estas estructuras tenían una continuidad en el trazado en las calles Alamos y Carretería, como se ha comprobado recientemente en esta última calle ${ }^{17}$, zona más vulnerable desde el punto de vista defensivo. Aunque no queremos entrar en dicho sondeo, cuyo articulo se publica en esta misma revista, si mencionar que este tramo correspondería a la obra del siglo $\mathrm{Xl}$, siendo de cronología posterior el primero.

\footnotetext{
16 Excavación realizada en la Plaza de la Marina..., dirigida por M. Acién.

17 Nota de prensa. Diario Sur, 20-12-1992.
} 
No se ha podido excavar, por el momento ninguna puerta de la muralla, cosa que sería bastante interesante para determinar cronologías, fábricas y características estructurales, como por ejemplo su disposición en recodo.

El paso de ronda, que se mantiene en el trazado de las calles Muro de Santa Ana y San Julián, también se ha detectado a intramuros en los sectores excavados, algunos de ellos ya de fábrica cristiana.

\section{CONCLUSIONES.}

Estas conclusiones van a suponer un punto de partida para proseguir la investigación sobre la muralla de Málaga, que prácticamente está en sus inicios.

Aunque la mayoría de las fuentes nos hablan de la edificación de la muralla islámica en el siglo Xl, de momento, ya que no contamos con ningún indicio documental ni arqueológico para el Emirato, parece iniciarse en la época califal, de cuya cronología se ha localizado un tramo en la actual calle Almacenes, con fábrica de sillares de arenisca unidos con argamasa y dispuestos a soga y tizón, zarpa también de sillares a soga y fosa de cimentación en la arena de la playa.

En esta época incluimos, con las debidas reservas, la estructura de piedras cuadradas de la plaza de la Merced, ya que la secuencia estratigráfica no es muy científica. Así quedarían los límites N. y S. de la ciudad califal, formando la línea costera ángulo, desde la calle Almacenes hasta el espigón natural de la plaza de la Marina. En este espacio de la Plaza de la Marina, se recoge una secuencia ininterrumpida desde el momento emiral, ocupado por una necrópolis y posteriormente por una serie de estructuras dedicadas a actividades portuarias, fuera del recinto murado cuyo trazado transcurriría más al interior.

Del siglo XI contamos con la cimentación de tapial cercana a la que posteriormente se conocerá como puerta de Granada. Así como la localizada en calle Carretería.
Será en época almohade, con el registro arqueológico de calle Alarcón Luján y Pasillo de Santa Isabel, y nazarí, detectado en la plaza de La Marina y calle Sagasta, frontera ésta de las Atarazanas, cuando se avanzará sobre la línea de costa (Lám. II). Suponiendo el último trazado de la muralla islámica, y por lo tanto de expansión de la ciudad hacia el mar. A partir de este momento, y a pesar de los intentos de mantener y reparar la muralla, ésta terminará sucumbiendo ante la misma expansión urbanística de la ciudad en los siglos XVIII y XIX que acaba por destruirla.

La muralla, intrínsecamente, se irá transformando adaptándose a las características defensivas y morfológicas de cada momento. Aunque el trazado en la zona interior se mantendrá con pocas variantes desde el siglo Xl, sí sufrirá modificaciones en la estructura y materiales.

\section{BIBLIOGRAFÍA}

ACIÉN ALMANSA, M. (1984a): "La formación y destrucción de Al-Andalus" en M. Barceló, dir., Historia de los pueblos de España. Tierras fronterizas (I) Andalucía. Canarias, Barcelona, pp. 21-45.

ACIÉN ALMANSA, M. (1984b): "De la conquista musulmana a la época nazarî", en Málaga, tomo I Historia, Granada.

ACIÉN ALMANSA, M. (1986): Cerámica a torno lento en Bezmiliana. Cronología, tipos y difusión, en Actas del I Congreso de Arqueología Medieval Española (Huesca 1985), t. IV, Zaragoza, pp. 243-267.

ACIÉN ALMANSA, M.; PERAL, C. y RECIO, A. (198990): "Informe preliminar de la intervención arqueológica efectuada en la calle Ollerías de Málaga". Mainake, XI-XII (1989-90), pp. 233-250.

\section{AL-IDRISI (1974): Geografía de España, Valencia}

AMATE DE LA BORDA, C. (1988): Compendiosa Noticia de lo que ha obrado en esta Ciudad de Málaga el Excmo. Sr. D. Fernando Carrillo Manuel, Marqués de Villafiel. Impreso en Málaga...Año de 1675, ed. facsímil de M. Olmedo Checa: Málaga a fines del siglo XVII, Málaga, 1988, p. 88.

BEJARANO ROBLES, F. ( 1984): Las calles de Málaga. De su historia y ambiente, vol. I, Málaga, 1984

BEJARANO ROBLES, F. (1985): Los Repartimientos de Málaga, vol. I, y II, Málaga. 
CABRERA PABLOS, F. y OLMEDO CHECA, F. (1988): El puerto de Málaga, Málaga.

DE LA CERDA, E.: Planos comparativos de Málaga. Carpeta Archivo Municipal de Málaga.

CHABANA, M.K. (1968): "Historia política del reinado del sultán Nasri Yusuf I" Miscelánea de Estudios Arabes y Hebraicos, Granada.

FERNÁNDEZ GUIRADO, M. I. (1988): "Informe del sondeo arqueológico en el solar de calle Sagasta $n^{\circ} 12$ (Málaga). Anuario Arqueológico de Andalucía. 1987. Actividades de Urgencia, T. III (1988), pp. 469-478.

GARCÍA DE LA LEÑA, C. (198I): Conversaciones históricas malagueñas, vol. III, Málaga, ed facsímil.

GARCÍA GÓMEZ, E.; LEVI-PROVENÇAL, E. (I980): EI siglo XI en primera persona. Las Memorias de Abd Allah, último Rey Zirí de Granada, destronado por los Almorávides (1090), Madrid.

GUILLÉN ROBLES, F. (1984): Málaga musulmana, vol. II, Málaga, p. 476, ed. facsímil.

IBN AL-JATIB ( 1977): Miyar al-ijtiyar fi dikr al-maahid waI-diyar ed. y trad. M.K. Chabana, Marruecos.

LADERO QUESADA M.A. (1979): Granada. Historia de un país islámico (| 232-157|), Madrid.

MACHUCA SANTA-CRUZ, L. (1987): Málaga, ciudad abierta. Origen, cambio y permanencia de una estructura urbana, Málaga, pp. 104-106.
MATA CARRIAZO, J. de (1940): Crónica de los Reyes Católicos por su secretario Fernando del Pulgar, vol. II, Madrid.

MORALES FLOGUERA, J.M.: (1986): La Málaga de los borbones, Málaga, 1986.

MORALES GARCÍA GOYENA, L (1906): Documentos históricos malagueños, vol. I, Granada.

NAVARRO LARA, M.R. (1988): "Informe del sondeo arqueológico llevado a cabo en el solar de la calle Pasillo de Santa Isabel n 8 de Málaga". Anuario Arqueológico de Andalucía. 1987. Actividades de Urgencia, T. III, pp. 449456.

OLMEDO CHECA, M. (1986): "Guadalmedina, Cartografía e Historia". Jábega, 5I, pp. 7I-80.

PASTOR, P. y PÉREZ, F. (1983): Informe sobre la excavación de la Plaza de la Merced. 1983. Inédito. Agradezco a sus autores la consulta de dicho informe.

PÉREZ-MALUMBRES, A. (en prensa): Sondeo Arqueológico en la muralla musulmana de Málaga en el solar de calle Alarcón Luján, n 3. En prensa.

TORRES BALBÁS, L. (1934): Torres Balbás: Ciudades Hispanomusulmanas. Vol. II, Madrid.

TORRES BALBÁS, L. (1982): "Excavaciones y obras en la Alcazaba de Málaga. 1934-1943" en Obra Dispersa, t. 3, Madrid.

VALLVÉ, J. (1966): "La historia de Ibn Askar. Una fuente importante de la Historia de Al- Andalus", Al-Andalus, $X X X \mid$ 


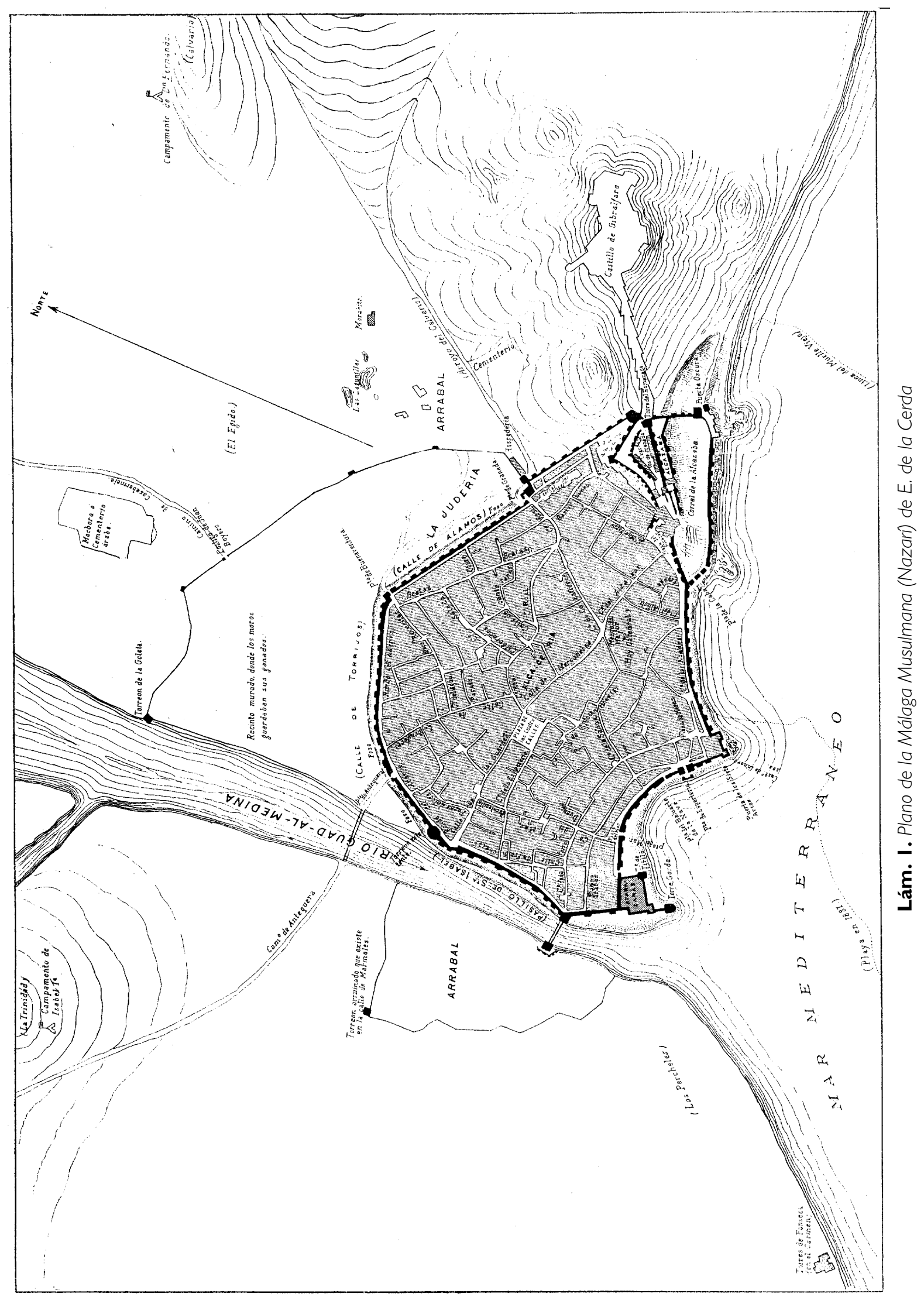




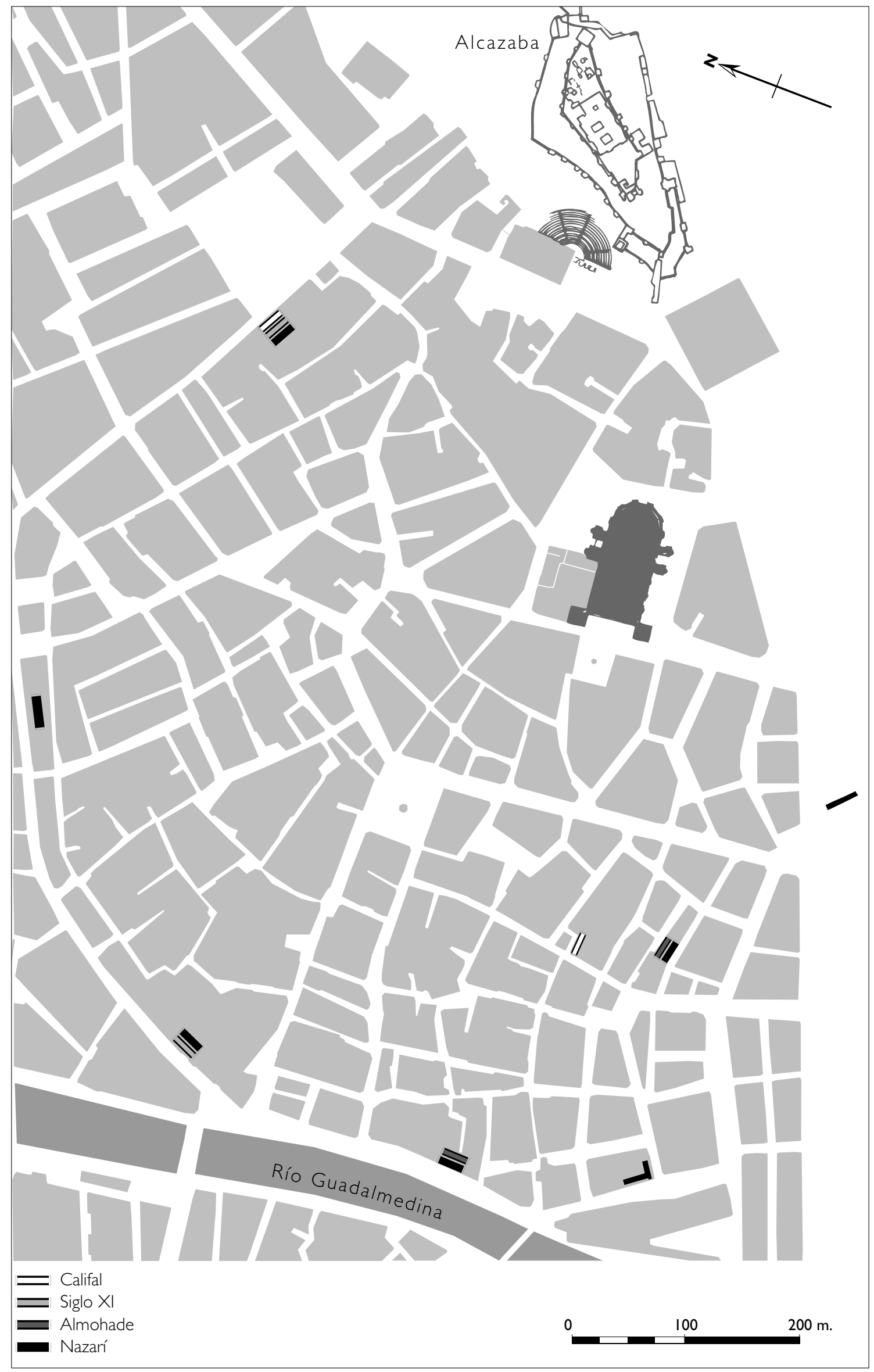

Lám. 2. Tramos de la Muralla excavados en Málaga 